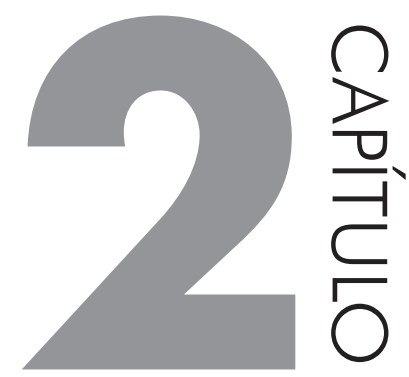

\title{
GLOSSÁRIOS REGIONAIS NORDESTINOS: um estudo lexicográfico
}

\section{ELINE MARIA MENDONÇA BULCÃO'1}

\section{INTRODUÇÃO}

Neste texto, sintetizamos nossa dissertação de mestrado (BULCÃO, 1993), defendida no segundo semestre de 1993, que se desenvolveu consoante três direcionamentos: (i) análise da nominata de nove glossários regionais nordestinos; (ii) tratamento de um subconjunto dessa nominata no dicionário AURÉLIO; e (iii) proposta para o estabelecimento de normas para a elaboração de um dicionário de regionalismos nordestinos.

Importa observar que, na época em que a referida dissertação foi escrita, apresentada e defendida, não havia, na Lexicografia brasileira, uma obra moderna de conjunto sobre as peculiaridades vocabulares regionais observáveis no Brasil. O que havia eram glossários, o léxico peculiar de um estado, de uma região,

\footnotetext{
Como primeira orientanda de Pós-graduação da Professora Silvia, quero manifestar meu profundo agradecimento por sua dedicação e apoio em cada etapa da dissertação e, sobretudo, ressaltar a admiração pela pessoa Silvia, grande amiga, grande referência ao longo destes mais de 25 anos.
} 
ou mesmo, de várias zonas do país. A dissertação arrola uma série deles, partindo de uma obra de 1852, da autoria de Antônio Álvaro Pereira Coruja, a Coleção de vocábulos e frases usadas na província de São Pedro do Rio Grande do Sul no Brasil e, sem pretensão de ser exaustiva, mas apenas de mencionar os trabalhos mais difundidos e conhecidos, chega até 1920. Esses foram também os únicos trabalhos de natureza dialectológica, correspondendo ao que se poderia denominar de fase lexical da Dialectologia brasileira.

Em 1920, publica-se o Dialeto caipira de Amadeu Amaral, marco do início de uma nova fase, que já demonstrava preocupação com o rigor científico. Contudo, verificamos que lamentavelmente o mesmo não aconteceu na Lexicografia regional. Até a época em que a dissertação foi escrita, não havia sido publicada uma obra elaborada com o critério e o método exigidos pela ciência da linguagem, mas continuaram proliferando os glossários estaduais, de 1922 a 1982.

De 1852 a 1982, segundo Pereira (1988, p. 18), os glossários mantêm uma mesma característica: "nasceram mais do apego ao berço nativo dos seus autores do que propriamente de uma preocupação científica de registro dos falares numa civilização em mudança". São trabalhos amadores, que desconhecem as normas da ciência lexicográfica, mas que, ao mesmo tempo, atestam "as divergências entre o linguajar brasileiro e o português" (TATI, 1975, p. 67).

Porque desconhecíamos a existência de estudos lexicográficos sobre os glossários regionais publicados no Brasil, vimos o interesse e a importância de uma dissertação sobre o tema, que focalizasse os glossários regionais nordestinos numa perspectiva lexicográfica. Limitamos a análise à nominata de nove glossários representativos de seis estados do Nordeste. O projeto inicial era mais ambicioso: fazer o levantamento e a análise de todas as entradas registradas nos glossários selecionados. Porém, a limitação de tempo a que fica sujeito qualquer trabalho para a obtenção de grau acadêmico, obrigou-nos a reduzir o corpus às entradas relativas a apenas três letras do alfabeto, o que redundou num total de 6.407 registros, material significativo para análise. Através de recursos da informática, o corpus foi sistematizado em listagens, tabelas e figuras, que fundamentaram as críticas e propostas.

A metodologia do trabalho assentou-se em dois estudos de Haensch; Werner (1978a, 1978b) a respeito da lexicografia regional: "Consideraciones sobre la elaboración de diccionarios de regionalismos; especialmente del español de America" (HAENSCH; WERNER, 1978a) e "Un nuevo dicionário de americanismos: proyecto de la Universidad de Augsburgo" (HAENSCH; WERNER, 1978b).

No desenvolvimento do trabalho, apresentamos uma análise descritivo-crítica da nominata dos nove glossários regionais, que evidencia o caráter amador dessas obras lexicográficas, sobretudo pela falta de critérios na seleção das entra- 
das e na recolha do material a ser registrado. A análise aponta os problemas decorrentes dessa ausência de critérios. Nesse sentido, a questão das entradas sintagmáticas tomou tal vulto que exigiu um tratamento à parte (realizado num capítulo especialmente a elas dedicado).

Ademais, o estudo investiga o tratamento que um subconjunto do corpus, formado por 1.431 registros, recebe no dicionário AURÉLIO (1986). Posteriormente, a pesquisa se estende - abarcando um grupo bem mais reduzido de termos - aos dicionários AULETE (1975) e LELLO, com o intento de investigar o tratamento de regionalismos brasileiros em dicionários portugueses.

Finalmente, apoiando-nos nos já referidos artigos de Haensch; Werner (1978), tecemos considerações sobre o estabelecimento de normas para a elaboração de um dicionário de regionalismos nordestinos. Nosso objetivo foi, sobretudo, apontar critérios para o aproveitamento com rigor científico do material recolhido nos glossários.

\section{ANÁLISE}

A etapa inicial do trabalho de levantamento dos glossários regionais publicados no Brasil foi feita na Biblioteca Nacional, nas Bibliotecas da Faculdade de Letras da UFRJ e da PUC e na Casa de Rui Barbosa. Não tivemos acesso a obras do Piauí, de Alagoas e de Sergipe e selecionamos nove glossários, publicados num período que vai de 1915 a 1982. Estão representados seis estados do Nordeste: Bahia, Ceará, Paraíba, Pernambuco e Rio Grande do Norte. Ceará, Paraíba e Pernambuco contam com duas obras cada um, o que tornou possível constatar se havia cópia entre esses glossários. A fim de realizar um confronto da nominata registrada nos nove glossários, foi criado um programa prévio de digitação constituído de nove campos. O computador utilizado para a digitação dos dados foi o UNISYS, do Núcleo de Computação Eletrônica, da UFRJ. Posteriormente, o confronto de dados foi feito num PC-386, utilizando-se a linguagem D-BASE.

A dissertação avança informando sobre as dificuldades encontradas durante a digitação de cada campo e quais as soluções encontradas. Tais dificuldades obrigavam a pesquisas como a consulta ao trabalho de WATBURG - Système raisonné des concepts pour servir de base à la lexicographie -, o que nos possibilitou determinar outros campos além daqueles previamente estabelecidos.

Estando já todo o material digitado, na fase segunda do trabalho, era chegado o momento do confronto dos dados obtidos. A linguagem informática D-BASE interativa possibilitou o cruzamento dos campos e a obtenção de resultados como, por exemplo, quantidade e relação de vocábulos por glossário, classe gramatical, campo conceitual, situação. Um dos dados de maior repercussão para o desenvolvimento do trabalho foi a observação de que o campo conceitual Homem 
psíquico era o mais produtivo, com 1431 registros. Esse campo foi selecionado para realizar o confronto com o dicionário Aurélio, a fim de verificar o tratamento que esses registros recebiam num dicionário geral da língua.

Cabe esclarecer que um dos objetivos desse trabalho era confrontar os dados obtidos nos glossários com os resultados apresentados no Atlas prévio dos falares baianos (APFB), no Atlas linguístico da Paraíba (ALPB) e no Atlas linguístico de Sergipe (ALS). Como apenas duas entradas se inseriram no campo conceitual Homem Psíquico, escolhido para o confronto das entradas com os dicionários gerais, preferiu-se abandonar esse propósito inicial e centrar o trabalho apenas no campo da Lexicografia.

O tema da elaboração de dicionários de regionalismos (discutido em capítulo específico da dissertação) resolveu de forma positiva a primeira questão focalizada: se seria pertinente falar nesse tipo de dicionários. Haensch; Werner (1978a), em seu estudo, afirmam que, ao se elaborar um dicionário de regionalismos, não se está pretendendo descrever um subsistema linguístico, e que, portanto, não haveria nenhuma razão teórica que impedisse a codificação de unidades léxicas fundamentada em critérios extralinguísticos. Logo a seguir, surge a questão relativa às unidades léxicas que fariam parte de um dicionário de regionalismos e sobre isso, na dissertação, há uma longa exposição, a partir da qual se concluem critérios e observações várias a respeito de palavras que designam coisas típicas da área estudada, pois, em relação a estas, é necessário haver rigorosa seleção para que não se sobrecarregue o dicionário com vocabulário típico de uso muito baixo. Nomes de animais, plantas, comidas, bebidas e termos técnicos menos conhecidos e até exóticos teriam lugar em outro tipo de obra, como num dicionário enciclopédico ou especializado em Zoologia ou Botânica, e não num dicionário linguístico descritivo.

Outra questão a que se respondeu na investigação foi sobre o modo de obter essas unidades léxicas. A resposta que mais interessou ao trabalho foi o aproveitamento de dicionários de regionalismos já publicados, não para fazer uma mera recopilação do material que neles havia, mas para um exame crítico do conteúdo dessas obras. Pôde-se comprovar o caráter pouco científico dos glossários regionais publicados no Brasil, quer pela ausência de critérios para a seleção de entradas, quer pela falta de métodos para a obtenção de material. Houve uma tentativa de utilização do critério contrastivo, mas o que prevaleceu foi o caráter amador dos mesmos. Os lexicógrafos brasileiros que decidissem elaborar um dicionário de regionalismos deveriam guiar-se pelas normas estabelecidas por Haensch; Werner (1978). Nesse sentido, a investigação propõe sugestões sobretudo no que diz respeito à forma de recorrer às obras lexicográficas já publicadas como método de obtenção de unidades léxicas. 
Da análise dos nove glossários selecionados, concluímos que, com exceção do Dicionário de brasileirismos; peculiaridades pernambucanas (1915), de Rodolfo Garcia, todos constituem trabalhos de lexicógrafos amadores. Seus autores não têm formação linguística, o que se revela em afirmações dos próprios quanto aos métodos utilizados para a seleção das entradas. A maioria tem como ponto de partida o próprio conhecimento da língua pelas suas andanças entre o povo e, embora haja intuição da necessidade da pesquisa de campo, percebe-se que não houve métodos para recolha de material. A par disso, é interessante notar que praticamente todos os autores intuem que a recolha de dados deve ser norteada por um critério de contrastividade. A dissertação tece observações sobre cada um dos glossários estudados, com apoio em tabelas e gráficos para a apresentação dos dados observados.

Quanto às entradas de natureza sintagmática, que também foram estudadas, expõe-se a dificuldade com que o lexicógrafo se depara quando, na macroestrutura, tem que atribuir a um determinado lema o registro de colocações usuais, unidades fraseológicas e idiomáticas. Na microestrutura, a unidade sintagmática apareceria como uma subentrada e o que o lexicógrafo teria de decidir seria a que lema da macroestrutura se vincularia o sintagma em questão. A dissertação apresenta diversas soluções a que o lexicógrafo poderia recorrer. Uma vez escolhida a solução, o lexicógrafo teria de dá-la a conhecer ao usuário na parte introdutória do dicionário, por meio de informações sobre o tratamento das unidades sintagmáticas. O estudo apresenta, ainda, seções nas quais se analisam como foram tratadas as unidades de natureza sintagmática nos glossários analisados.

A questão dos regionalismos no Português do Brasil também foi tema da investigação. Parte-se do princípio, na época em que a dissertação foi elaborada e defendida, de que ainda não era possível determinar com rigor as áreas lexicais brasileiras. Sendo assim, a tarefa de determinar os brasileirismos e, entre estes, os regionalismos, pareceu inviável naquele estágio dos estudos sobre a variante brasileira. Serafim da Silva Neto $(1950$, p. 26) já alertara que muitos termos consagrados como brasileirismos deixaram de ser assim considerados com a publicação de glossários regionais portugueses. Paiva Boléo (1943, p. 68) já escrevera sobre a possibilidade de que muitos brasileirismos afinal poderiam ser dialetismos lusitanos.

Aurélio Buarque De Holanda Ferreira foi um dos lexicógrafos que mais contribuiu para o registro de brasileirismos, principalmente na segunda edição do Novo dicionário da Lingua Portuguesa, em 1986. No prefácio do dicionário, faz-se breve referência aos regionalismos quando se diz que não se desprezou esse tipo de vocábulo na recolha do material, mas não há informações sobre o método de seleção de entradas, nem sobre os meios de obtê-las. A dissertação passa, então, a examinar se os termos registrados nos glossários regionais estão compilados 
como regionalismos no dicionário AURÉLIO, segunda edição, de 1986, por ser, na época, a mais recente obra do autor. Restringiu-se a análise a um só campo conceitual e a escolha recaiu sobre o campo semântico Homem Psíquico, o mais produtivo. Depois de verificar, no Aurélio, se havia o registro de cada uma das 1431 entradas que constituem o referido campo, e, em caso afirmativo, como era classificada a unidade lexical, estabelecemos cinco grupos. Das 1.431 entradas selecionadas, 477 foram consignadas como brasileirismos, o que corresponde a $33 \%$ do total. Há figuras, listagens e minuciosas análises sobre esses dados.

Com o avanço da investigação, importa reconhecer que já existe um tesouro lexicográfico de brasileirismos compendiado em dicionários gerais da língua e em glossários regionais, apesar das ressalvas que a questão suscita. Inegável é também que, com as fontes de que se dispõe, esse tesouro não poderia estar trabalhado de outra forma, sobretudo por aqueles lexicógrafos brasileiros que merecem tal título. É, contudo, incontestável que o tesouro de brasileirismos não é canônico e o seu aproveitamento como fonte de outras obras lexicográficas deve ser feito com muita cautela. Crítica merece, portanto, um projeto de pesquisa da Universidade do Rio Grande do Norte (PASSEGI, 1993) que oferece uma metodologia para a dicionarização de glossários regionais sem questionar o material neles recolhido.

Sempre com base nos pressupostos teórico-metodológicos de Haensch \& Werner (1978), foi possível abordar no trabalho dois pontos: (i) a natureza de um dicionário de regionalismos nordestinos; e (ii) o aproveitamento do material registrado nos glossários regionais nordestinos já publicados.

No que se refere ao primeiro ponto, foi preciso determinar o que se entenderia por unidades léxicas da região Nordeste. Antenor Nascentes (1953) dividiu o Brasil em seis subfalares reunidos em dois grupos: Norte e Sul. Utilizando-se, como ponto de partida, a divisão proposta por Nascentes para o subfalar nordestino, quais seriam as unidades léxicas a serem registradas num dicionário de regionalismos nordestinos? Para tanto, fez-se necessário escolher uma das possibilidades de contraste de que tratam Haensch; Werner: registrar unidades léxicas que se dão na área em questão, mas não se dão em nenhuma parte no resto do país, seria a mais adequada. Por outro lado, como Serafim da Silva Neto observou que a publicação de glossários regionais portugueses diminui, dia a dia, o número de brasileirismos (1950, p. 26), ter-se-ia de estender o critério de contraste também a Portugal. Teoricamente, a questão fica resolvida, mas sua prática é inviável, pelo menos no estágio atual dos estudos lexicográficos e dialetológicos sobre o Português do Brasil.

Se é inexequível a proposta de elaboração de um dicionário de regionalismos nordestinos em sentido estrito, por outro lado, urge proceder a um trata- 
mento menos impressionista das variedades de natureza geográfica da Língua Portuguesa no Brasil. A primeira tarefa a realizar é o aproveitamento do material existente nos glossários publicados com vista à elaboração de um futuro dicionário de regionalismos nordestinos. Trata-se, na verdade, de uma primeira triagem, a fim de verificar se são ou não brasileirismos os termos recolhidos nessas obras de referência.

Quanto ao segundo ponto, restou claro que o material oriundo de obras de referência deve ser submetido a um exame crítico. A proposta de Haensch; Werner (1978) é que este material seja examinado por colaboradores que conheçam a fundo o uso linguístico da área estudada e a dissertação especifica o que cada colaborador teria de averiguar.

\section{CONSIDERAÇÕES FINAIS}

Espera-se que o relato da pesquisa desenvolvida por Bulcão (1993) possa ter demonstrado o teor das reflexões e da contribuição - respeitados os limites do período da investigação - do referido trabalho à área da Lexicografia. A título de sistematização, cabe reproduzir e destacar os oito tópicos elencados no item conclusivo da dissertação, em que se sintetizam as contribuições decorrentes dos passos decisivos para a realização do referido trabalho:

1. Os glossários regionais nordestinos foram pela primeira vez focalizados numa perspectiva lexicográfica, o que permitiu comprovar o amadorismo com que foram realizados.

2. A metodologia empregada para a análise lexicográfica é precursora e pode servir de modelo para trabalhos da mesma natureza.

3. A verificação do tratamento que recebeu um segmento do corpus em dicionários gerais da Língua Portuguesa levantou dúvidas quanto à seriedade científica da classificação de brasileirismos ou regionalismos que algumas unidades léxicas neles receberam. Comprovou-se a fragilidade das informações que contêm os glossários e os dicionários gerais e demonstrou-se a impossibilidade de os lexicógrafos brasileiros oferecerem uma classificação fidedigna do léxico do ponto de vista diatópico.

4. Os dados revelam a necessidade de realizar-se uma obra moderna e séria sobre a lexicografia regional brasileira, sendo para isso imprescindível que se fixe, com rigor, o conceito de brasileirismo e, em consequência, o de regionalismo.

5. O trabalho constitui, fundamentalmente, a primeira contribuição para que se realize empresa de tal vulto. Com base nos princípios estabelecidos 
pela equipe de Augsburgo, apresentaram-se as linhas gerais que devem nortear a consecução de um dicionário de regionalismos nordestinos e, por extensão, a de obras lexicográficas da mesma natureza.

6. Ofereceu-se, ainda, uma metodologia para aproveitamento do material compilado nos glossários regionais existentes, que, apesar das falhas que contêm, poderiam servir de ponto de partida para a recolha de dados e a seleção de entradas.

7. Apontam-se providências preliminares a serem tomadas, tais como a formação de uma equipe de lexicógrafos com amplos conhecimentos sobre o léxico da protovariante e da variante brasileira, bem como - dependendo da área em estudo - das suas variedades regionais.

8. Para que se proceda, com rigor, ao registro do tesouro lexical brasileiro por regiões, é necessário que, previamente, se empreenda, em nosso país, uma pesquisa semelhante à realizada em Portugal para levantamento e determinação do léxico fundamental, com base em critérios de frequência.

\section{REFERÊNCIAS BIBLIOGRÁFICAS}

AMARAL, Amadeu. O dialeto caipira. 3. ed. São Paulo: Huitec, Secretaria de Ciência e Tecnologia, 1976.

AULETE, Caldas. Dicionário contemporâneo da Lingua Portuguesa. 4. ed. Rio de Janeiro: Delta, 1958.

BOLÉO, Manuel de Paiva. Brasileirismos: problemas de método. Coimbra: Coimbra Editora, 1943.

BULCÃO, Eline Maria Mendonça. Glossários Regionais Nordestinos: um estudo lexicográfico. 1993. Dissertação (Mestrado em Língua Portuguesa) - Faculdade de Letras, Universidade Federal do Rio de Janeiro, Rio de Janeiro, 1993.

FER REIRA, Aurélio Buarque de Holanda. Novo dicionário da Lingua Portuguesa. 15. reimpressão. Rio de Janeiro: Nova Fronteira, 1975. 1986.

. Novo dicionário da Lingua Portuguesa. 2. ed. Rio de Janeiro: Nova Fronteira,

GARCIA, Rodolfo. Dicionário de brasileirismos; peculiaridades pernambucanas. Separata da Revista do Instituto Histórico Geográfico Brasileiro, v. 76. Rio de Janeiro: Imprensa Nacional, 1915.

HAENSCH, Guenther; WERNER, Reinhold. Consideraciones sobre la elaboración de diccionarios de regionalismos; especialmente del español de America. Boletín de filologia, Santiago de Chile, XXIX, p. 351-363, 1978a.

. Un nuevo dicionário de americanismos: proyecto de la Universidad de Augsburgo. THESAURUS, Bogotá, 33(1), p. 1-40, 1978b. 
MELLO, Gladstone Chaves de. Dicionários portugueses. Rio de Janeiro: S.D. do M.E.S, 1947.

NASCENTES, Antenor. O linguajar carioca. 2. ed. Rio de Janeiro: Simões, 1953. . Bases para a elaboração de um atlas linguístico do Brasil. Rio de Janeiro: Casa de Rui Barbosa, 1958, parte 1; 1961, parte 2.

PEREIRA, Cilene da Cunha. Os pescadores da Lagoa de Araruama: etnografia e linguagem. Tese (Doutorado em Língua Portuguesa) - Faculdade de Letras, Universidade Federal do Rio de Janeiro, Rio de Janeiro, 1988.

SILVA NETO, Serafim. Introdução ao estudo da Lingua Portuguesa no Brasil. 3. ed. Rio de Janeiro: Presença; Brasília: INL, 1976. . Manual de filologia portuguesa. 2. ed. Rio de Janeiro: Acadêmica, 1957.

TATI, Miécio. A lexicografia no Brasil. In: MIRADOR INTERNACIONAL, 1975. Rio de Janeiro, Encyclopaedia Britannica do Brasil v. 13, 1975, p. 6758-6760.

WARTBURG, Walther von; HALLIG, Rudolf. Système raisonné des concepts pour server de base à la lexicographie. Berlin: Academie-Berlag, 1963.

ZGUSTA, Ladislav. Manual of lexicography. Prague: Academia; The Hague: Mouton, 1971. 
